\title{
Effect of Anti-Emetic Combination of Sevoflurane / Propofol Anesthesia Technique in Laparoscopic Cholecystectomy
}

Muhammad Salman Maqbool, Muhammad Alam, Muhammad Umer Draz, Ayesha Shahid, Shumaila Ashfaq

ABSTRĀTT:

Objective: To assess symptoms of nausea and vomiting in laparoscopic cholecystectomy post-operatively, administered anesthesia by sevoflurane or propofol and to assess the effect of dexamethasone and ondansetron anti-emetic combination.

Study design \& Setting: It was an experimental study design conducted from 08-Oct-2017 till 11-Jul-2018 at Rawal General \& Dental Hospital.

Methodology: Patients were recruited in interventional groups by lottery method as $n=160$, with 80 cases allocated in each group. The patients with gallstones planned for laparoscopic cholecystectomy after preoperative assessment were classified to American Society of Anesthesiologist (ASA) physical status class I-II. All the patients placed in a particular ASA physical status class were (exposed to both induction methods) either anesthetic induction by propofol $1-2 \mathrm{mg} / \mathrm{kg}$ (group-A) or by employing sevoflurane 4-8\% (group-B) in combination with oxygen, while maintenance was done in both study groups with $2 \%$ sevoflurane and $50 \%$ nitrous oxide in oxygen. After procedure patients stayed in post-anesthesia care unit where intra-operative monitoring was evaluated. The primary end point of the study was to note the rate of nausea and vomiting in 24 hours interval after surgery.

Results: Both sevoflurane and propofol are equally effective anesthetic induction agents. The same combination of dexamethasone and ondansetron was given to both groups and so the actual effect of both anesthesia drugs in terms of side effects were nullified.

Conclusion: In laparoscopic cholecystectomy, both sevoflurane and propofol are good enough when administered with dexamethasone and ondansetron anti-emetic combination, for post-operative nausea and vomiting up to 24 hours observation time in study.

Keywords: Propofol, Nausea, Laproscopic cholecystectomy, Sevoflurane.

How to cite this Article:

Maqbool MS, Alam M, Draz MU, Shahid A, Ashfaq S. Effect of Anti-Emetic Combination of Sevoflurane / Propofol Anesthesia Technique in Laparoscopic Cholecystectomy. J Bahria Uni Med Dental Coll. 2022; 12(1):3-7 DOI: https://doi.org/10.51985/JBUMDC2021046

- - - - - - - - - - - - - - - - - - - - - - - - - This is an Open Access article distributed under the terms of the Creative Commons Attribution Non Commercial License (http:// creativecommons/org/licences/by-nc/4.0) which permits unrestricted non commercial use, distribution and reproduction in any medium, provided the original work is properly cited.

- - - - - - - - - - - - - - - - - - - - - - - - - - -

I

Muhammad Salman Maqbool

I Professor \& Head Department of Anaesthesia,

Islam Medical \& Dental College, Islam Teaching Hospital,

Pasroor Road, Sialkot

I Email: muhammadsalman590@gmail.com

I Muhammad Alam

I Associate Professor, Department of Surgery

Rawal Institute of Health Sciences, Islamabad

I

Muhammad Umer Draz

Senior Registrar, Department of Medicine

I Medical Unit-11, Holy Family Hospital, Rawalpindi

I Email: Drayesha_kemu@hotmail.com

I Ayesha Shahid

Assistant Professor.Department of Anesthesia

- Rawal Institute of Health Sciences, Rawal General \& Dental

I Hospital, Islamabad

I Email: mumer@gmail.com

I Shumaila Ashfaq

Assistant Professor, Department of Anesthesia

Islam Medical \& Dental College, Islam Teaching Hospital,

I Sialkot

I Email: Shumailaashfaq24@gmail.com

I Received: 16-Aug-2021

Accepted: 13-Dec-2021

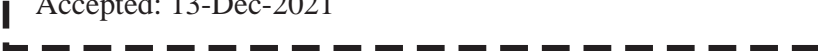

\section{INTRODUCTION:}

This is an era of modern surgery and laparoscopic cholecystectomy has become the preferred method for gall stones disease. ${ }^{1}$ As the relative risk of cholelithiasis is around $10-15 \%$, while relapse rate of symptoms and its complications is around 35\% while major advantage with laparoscopic technique is reduce length of hospital stay, early recovery and better cosmetic results. ${ }^{2}$ Nausea and vomiting postoperatively remains the most frequent complication and estimated that approximately $20-30 \%$ of patients suffer from this issue after surgical procedures done under general anesthesia. ${ }^{3}$ Factors contributing to postoperative nausea and vomiting are patient factors (previous history of motion sickness, obesity, female gender), surgical factors like surgeries causing peritoneal irritation such as laparoscopic procedures, anesthetic factors (use of volatile agents, duration of anesthesia and narcotic analgesics). ${ }^{4.5}$ It can be troublesome to the patient, sometimes more than the surgery itself and may lead to complications like dehydration, acid base disorders, gastric aspiration and wound disruption. ${ }^{6}$

The two commonly administered corticosteroids (dexam- 
ethasone and methyl-prednisolone) are consumed as antiemetics and effect is particularly enhanced when dexamethasone with ondansetron combination is used. ${ }^{4}$ Dexamethasone $4-10 \mathrm{mg}$ given by intra-venous route at induction of anesthesia and there is no convincing data that it causes delayed wound healing or adrenocortical suppression after one dose pre-operatively. Nausea and vomiting are physiological phenomenon and needs co-ordination of various organ systems ranging central nervous system to gastro-intestinal system and serotonin 5-hydroxy tryptamine receptors (5HT3) located in chemoreceptor trigger zone, vomiting center in medulla and peripherally in nerves conducting impulses from vagus and spinal nerves to brain. ${ }^{4}$ The 5HT3 receptor blockers used prophylactically as well as in treatment of post-operative nausea and vomiting. Ondansetron is frequently administered 5HT3 receptor blocker and mostly given as $4-16 \mathrm{mg}$ intra-venously prophylactically at induction of anesthesia, however studies show it to be more effective if given after surgery before shifting of patient from operating room as the doses used in this study. Some studies show dose of $4 \mathrm{mg}$ to be effective as prophylactic treatment of post-anesthesia nausea and vomiting, whereas other studies demonstrated $8 \mathrm{mg}$ dosage., ${ }^{4,7}$

Sevoflurane has fast onset and smooth on induction and also used in maintenance phase of anesthesia as part of balanced technique, preferably used for inhalational induction in adults as well as children. ${ }^{4}$ It is sweet smelling volatile anesthetic, non-irritant with rapid onset, delivers optimal hemodynamic stability. ${ }^{4,8,9}$ Propofol is also a frequently employed intravenous anesthetic induction agent. ${ }^{8,9}$

Fredman $\mathrm{B}^{10}$, et al. did a study comparing three different anesthetic techniques in day-case surgery including sevoflurane, propofol, they stated that sevoflurane is a appropriate substitute to propofol as part of balanced anesthesia agent in ambulatory surgery cases. Keeping in view above consideration this study was configured to assess frequency of nausea and vomiting post-operatively (at 24 hours interval) employing diverse anesthesia induction modalities (propofol and sevoflurane ${ }^{9}$ ) in laparoscopic cholecystectomy keeping anesthesia maintenance methods same and employing anti-emetic regimen combination (dexamethasone and ondansetron) can address the issue of post-operative nausea and vomiting. Hence, the primary objective was to assess symptoms of nausea and vomiting in laparoscopic cholecystectomy post-operatively in 24 hours interval after surgery by administering anesthesia of sevoflurane or propofol and to assess the effect of dexamethasone and ondansetron as an anti-emetic combination.

\section{METHODOLOGY:}

The study was conducted at Rawal General Hospital (Rawal Institute of Health Sciences) main laparoscopic surgical theatre, Islamabad from 8-Oct-2017 till 11-July-2021 after ethical board approval from Dean Ethical Board, ref vide RIHS-REC/003/17. The sampling technique was purposive. The sample size was calculated employing $5 \%$ margin of error with $80 \%$ level of confidence and using Rao-soft sample size calculator and came out to be 80 cases in each group. ${ }^{8}$ Patients were recruited in interventional groups by lottery method as $n=160$, with 80 cases allocated in each group . The patients with gallstones planned for laparoscopic cholecystectomy had a standard pre-operative assessment in outdoor anesthesia clinic and placed in American Society of Anesthesiologist ${ }^{11}$ (ASA) physical status class I-II. Informed consent was taken off for the study. All the patients placed in a particular ASA physical status class were (exposed to both induction methods) either anesthetic induction by propofol 1-2 mg/kg (group-A) or by employing sevoflurane $4-8 \%$ (group-B) in combination with oxygen, while maintenance was done in both study groups with $2 \%$ sevoflurane and 50\% nitrous oxide in oxygen. ${ }^{12,13}$ Inclusion criteria was patients with gall stones and in ASA physical status class I-II. Exclusion criteria was patients with acute viral hepatitis, morbid obesity and ASA class III and IV. ${ }^{12}$ In operating room large bore intravenous cannula was placed, electrocardiograph, pulse oximetry, end-tidal $\mathrm{CO}_{2}$ and blood pressure monitoring was initiated. General anesthesia was begun with co-induction ${ }^{14,15}$ by injection nalbuphine $10 \mathrm{mg}$ plus midazolam in dose of $0.01 \mathrm{mg} / \mathrm{kg}$ in all cases. This was followed by either propofol (group-A) or by sevoflurane(group-B). All patients in study received ondansetron $4 \mathrm{mg}$ at time of induction of anesthesia and before extubation, in addition dexamethasone $8 \mathrm{mg}$ used at induction of anesthesia. Endotracheal intubation was done by giving atracurium injection $0.5 \mathrm{mg} / \mathrm{kg}$. At induction and anesthetic recovery time along with dexamethasone $8 \mathrm{mg}$ at start as anesthetic adjunct whereas tracheal intubation was facilitated by $0.5 \mathrm{mg} / \mathrm{kg}$ atracurium. At the end of procedure patients were kept under observation in post-anesthesia care unit. Patients were shifted later to respective ward as per clinical evaluation. SPSS version 23 was used for data analysis. Primary outcome parameter investigated was frequency of nausea and vomiting in 24 hours interval postsurgery. The secondary end points included use of analgesics, duration of surgery, and any complications. Mean \pm S.D, frequencies and percentages are presented for variables e.g., age and gender.

\section{RESULTS:}

The age, induction with operative time, was shown in table1. Both sevoflurane and propofol are equally effective anesthetic induction agents. Hence, both groups had same with no symptoms of post-operative nausea and vomiting after surgery in the twenty-four-hour observation time period at all. Pearson correlation determines the affiliation between two variables, value of correlation co-efficient $(r=0.492)$ and was significant at 0.01 level. The same combination of dexamethasone and ondansetron was given to both groups 
and so the actual effect of both anesthesia drugs in terms of side effects were nullified. Two cases were diagnosed as Mirizzi syndrome (as depicted in figure- 1 and 2 respectively) and one had to be switched to open technique as there were anatomical difficulty in continuing laparoscopic approach and excluded from study. Gender ratio is shown in table-2. In 8 cases $(5 \%)$ post-operative analgesics were needed and in 172 cases $(95.55 \%)$ of study no analgesics were needed. The ASA ${ }^{11}$ grades are depicted in table- 3 .

\section{DISCUSSION:}

Sevoflurane utilization for induction is often times linked with a higher risk of post-surgical nausea / vomiting than propofol based out-patient anesthetic technique but use of antiemetic medications can decrease its incidence. ${ }^{16}$ Another

Table - 1; Age and operative data. $(\mathrm{n}=80)$

\begin{tabular}{|l|l|c|c|}
\hline & Age(years) & $\begin{array}{c}\text { Induction to loss } \\
\text { of consciousness } \\
\text { (minute) }\end{array}$ & $\begin{array}{c}\text { Surgery time } \\
\text { (minutes) }\end{array}$ \\
\hline & \multicolumn{3}{|c|}{ Group -A / Group -B } \\
\hline Mean & $44.38 / 44.73$ & $1.13 / 1.29$ & $55 / 60.77$ \\
\hline Std. Deviation & $13.81 / 14.36$ & $0.33 / 0.60$ & $30.90 / 39.71$ \\
\hline
\end{tabular}

Figure 1: Mirizzi Syndrome. (Diagrammatic view A \& B)
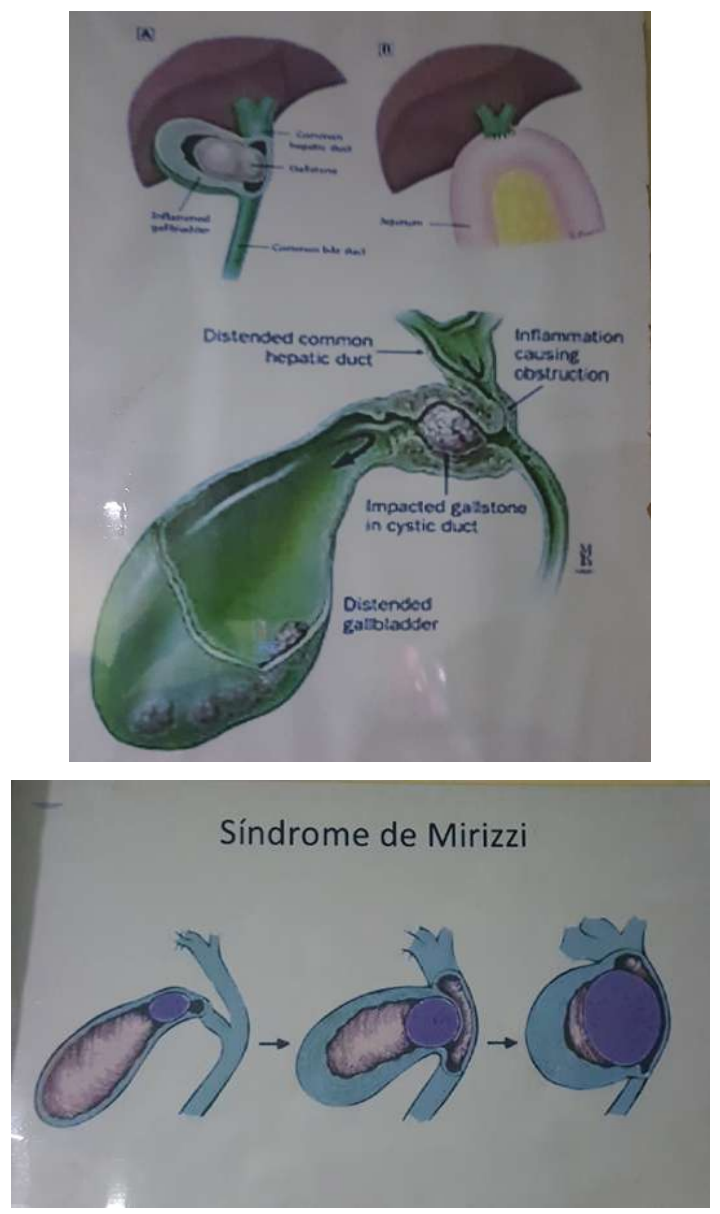

Figure 2: Gall bladder with stones Mirrizi syndrome

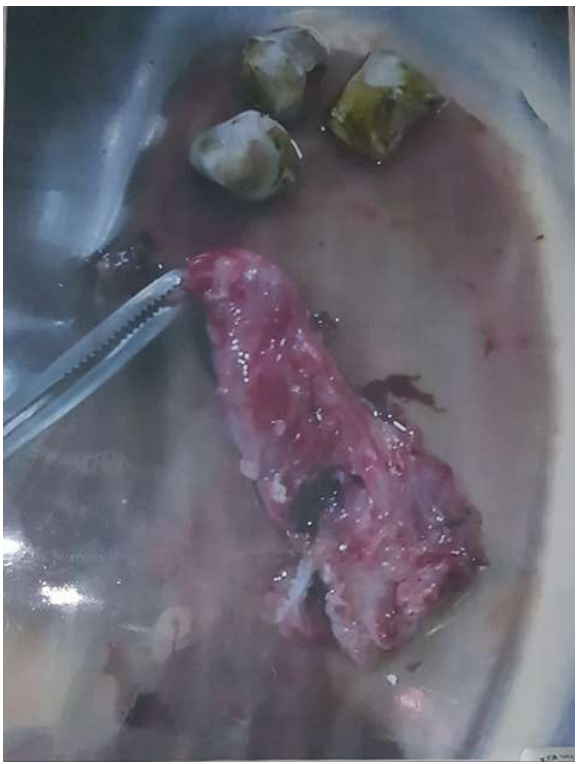

Table 2: Gender distribution $(\mathrm{n}=80)$

\begin{tabular}{|l|c|c|}
\hline \multirow{2}{*}{} & \multicolumn{1}{|c|}{ Males } & Females \\
\cline { 2 - 3 } & \multicolumn{2}{|c|}{ Group-A / Group-B } \\
\hline Number & $16 / 13$ & $64 / 67$ \\
\hline Percent (\%) & $20 / 16.25$ & $80 / 83.75$ \\
\hline
\end{tabular}

Table 3: ASA grades. $(\mathrm{n}=80)$

\begin{tabular}{|c|c|c|}
\hline \multirow{2}{*}{} & Group-A & Group-B \\
\cline { 2 - 3 } & \multicolumn{2}{|c|}{ Number / percent } \\
\hline ASA-grade-I & $48 / 60 \%$ & $51 / 63.75 \%$ \\
\hline ASA-grade-II & $32 / 40 \%$ & $29 / 36.25 \%$ \\
\hline
\end{tabular}

study stated that various anesthetic practices (depending on anesthetic facilities and expertise) are being used in day case and in-patient(elective) laparoscopic gallstone surgery, with insufficient information to configure ideal one ${ }^{17}$, in this study various induction methods were used. In another study it was stated that dexamethasone given at time of anesthesia induction significantly reduces prevalence of vomiting at laparoscopic procedures. ${ }^{18}$

Keeping intra-abdominal pressure (kept below $10 \mathrm{~cm} \mathrm{H}_{2} \mathrm{O}$ in all cases of study) is stated as an important factor in reducing frequency of post-operative nausea. ${ }^{9}$ In study done by Gautam $\mathrm{B}^{19}$ and colleagues they pointed out that combination of ondansetron with dexamethasone was more effective (regimen used in our study) as a prophylactic against nausea / vomiting in laparoscopically removal of gallbladder as compared to both drugs alone. $\mathrm{Yu} \mathrm{WY}^{20}$ and colleagues in their study concluded that ondansetron is effective in prevention and cure of postoperative nausea and vomiting associated with laparoscopic 
cholecystectomy procedure with late administration of ondansetron at anesthetic recovery time to be significantly more effective, a regimen followed in this study. In a single case in study on shifting in post anesthesia care area low pulse oximeter saturation of $73 \%$ was noted, which immediately improved by administering $60 \%$ venturi mask oxygen with patient in head-up, position and by injection hydrocortisone $100 \mathrm{mg}$ intravenously. In this study various anesthesia induction techniques were adopted while keeping balanced anesthetic and antiemetic combination uniform and notable that no significant difference existed employing propofol vs sevoflurane induction technique groups, as regard to symptoms nausea and vomiting after laparoscopic cholecystectomy. Another study fully elucidated various available modalities including acupuncture, single versus multi-modal anti-emetic prophylaxis, however they stated that effectiveness of various therapeutic technique will need further studies. ${ }^{21,22}$ In another study, comparing single antiemetic use(ondansetron) with combination therapy (ondansetron with dexamethasone) for efficacy against postop nausea and vomiting, in laparoscopic gall stones surgery, they reported dual anti-emetic showing better results, in this study two combination medications were will come utilized with promising results ${ }^{23}$. Another study, employed balanced anesthesia technique gallstones laparoscopic surgery in patients with co-morbid diseases ${ }^{24}$ along with anti-emetic combination (regimen used in this study) with good effect. In another study, it was depicted that for antiemetic prophylaxis in laparoscopic cholecystectomy, dexamethasone in combination with other agent was superior than single anti-emetic administration ${ }^{25}$. The study had limitation that it was not on a large scale, as multiple factors are implicated as cause of nausea and vomiting, secondly ASA grade III and IV, morbid obesity cases were not extrapolated in our study.

\section{CONCLUSION:}

In laparoscopic cholecystectomy, both sevoflurane and propofol are good enough when administered with dexamethasone and ondansetron anti-emetic combination, for post-operative nausea and vomiting up to 24 hours observation time in study.

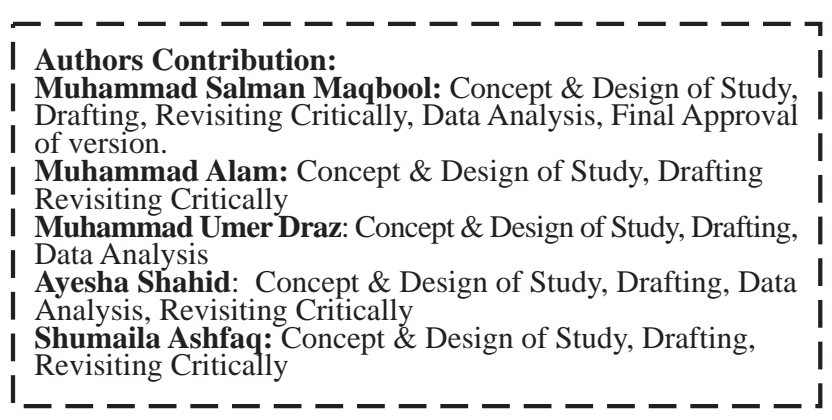

\section{REFERENCES:}

1. Di Buono G, Romano G, Galia M, Amato G, Maienza E, Vernuccio F, Bonventre G, Gulotta L, Buscemi S, Agrusa A. Difficult laparoscopic cholecystectomy and preoperative predictive factors. Sci Rep. 2021;11(1):2559. https://doi.org/ 10.1038 /s41598-021-81938-6.

2. Majumder A, Altieri MS, Brunt LM. How do I do it: laparoscopic cholecystectomy. Ann Laparosc Endosc Surg 2020: 5;5766. https://doi:10.21037/ales.2020.02.06

3. Hsieh CY, Poon YY, Ke TY, Chiang MH, Li YY, Tsai PN, Wu SC. Postoperative Vomiting Following Laparoscopic Cholecystectomy Is Associated with Intraoperative Fluid Administration: A Retrospective Cohort Study. Int. J. Environ. Res. Public Health 2021, 18, 5305. https://doi.org/ 10.3390/ ijerph18105305

4. Sikka PK, Beaman ST, Street JA. Basic Clinical Anesthesia. Springer 2015; (II):123-65.

5. Farda W, Tani M.K, Manning RG, Fahmi MS, Barai N et al. Laparoscopic cholecystectomy: review of 1430 cases in Cure International Hospital, Kabul, Afghanistan. BMC Surg 2021:21; 344. https://doi.org/10.1186/s12893-021-01342-9

6. Zackria R, Lopez RA. Postcholecystectomy Syndrome. 2021 Sep 2. In: StatPearls [Internet]. Treasure Island (FL): StatPearls Publishing; 2021 Jan-. PMID: 30969724.

7. Liu Q, Zhou C, Bao Z, Zhu Y. Effects of palonosetron and ondansetron on preventing nausea and vomiting after laparoscopic surgery. J Int Med Res. 2018;46(1):411-420. https://doi:10.1177/0300060517715374.

8. Maqbool MS, Alam M, Ayesha. Post-Operative Recovery Profile after Laproscopic Cholecystectomy: Comparing Inhalational Versus Intravenous Anaesthetic Regimen. JRMC 2019;23(1):38-42.

9. Maqbool MS, Alam M, Draz MU, Shahid A, Ashfaq S. Anaesthesia Concern in High-Risk Cases Under Going Ambulatory Laparoscopic Cholecystectomy. J Bahria Uni Med Dental Coll. 2021; 11(4):179-183. https://doi.org/ 10. 51985/JBUMDC2021045

10. Fredman B, Nathanson MH, Smith I, Wang J, Klein K, White PF.Sevoflurane for outpatient anesthesia: a comparison with propofol.Anesth Analg 1995;81:823-8. https://doi:10.1097 /00000539-199510000-00028.

11. Morgan GE, Mikhail MS.Clinical Anesthesiology.5th Edition.McGraw Hill Education 2013;18:297.

12. Manzia TM, Quaranta C, Filingeri V, Toti L, Anselmo A, et al. Feasibility and cost effectiveness of ambulatory laparoscopic cholecystectomy. A retrospective cohort study. Ann Med Surg. 2020; 55:56-61. https://doi.org/10.1016/j.amsu. 2020.04.036.

13. Nadri S, Karimi A, Mohammadi F, Mahmoudvand H. A randomized controlled trial evaluating inhalation and intravenous anesthesia for laparoscopic cholecystectomy. Int. J. of Surg. Open 2021;28:1-7. https://doi.org/ 10.1016/j.ijso. 2020.12.001.

14. Ababneh OA, Suleiman AM, Bsisu IK, Al-Ghanem SM, Samarah WK, Al-Zaben KR, Qudaisat IY, Khreesha LA, Al Edwan GM, Murshidi MM. A Co-Induction Technique Utilizing 4\% Sevoflurane Followed by $0.75 \mathrm{mg} / \mathrm{kg}$ Propofol in Elderly Patients Undergoing Minimally Invasive Procedures: A Prospective Randomized Control Study. Medicina (Kaunas). 2020;56(12):682. https://doi.org/10.3390/medicina56120682. 
15. Nagalakshmi P, Leo S, Uthirapathi S. Use of Butorphanol, Fentanyl, and Ketamine as Co-Induction Agents with Propofol for Laryngeal Mask Airway Insertion: A Comparative Study. Anesth Essays Res. 2018;12(3):729-734. https://doi.org/ 10.4103/aer.AER_104_18.

16. Matsuura $\mathrm{H}$, Inoue $\mathrm{S}$, Kawaguchi $\mathrm{M}$. The risk of postoperative nausea and vomiting between surgical patients received propofol and sevoflurane anesthesia: A matched study. Acta Anaesthesiol Taiwan. 2016;54(4):114-120. https://doi: 10.1016/j.aat.2016.09.002.

17. Bernardo, S, Vieira, A, Vieira, V 2018 Challenging the Anaesthetic Technique for Laparoscopic Cholecystectomy in Ambulatory Surgery. Ambul 2017; 12:94-97.

18. Sharma S, Gnanasekar N, Kurhekar P. Comparison of dexamethasone, granisetron and haloperidol in prevention of postoperative nausea and vomiting following laparoscopic surgeries: A prospective, double-blinded study. Glob J Anesth 2019;6(1):2-5. http://doi.org/10.17352/2455-3476.000045

19. Gautam B, Shrestha BR, Lama P, Rai S. Antiemetic prophylaxis against postoperative nausea and vomiting with ondansetrondexamethasone combination compared to ondansetron or dexamethasone alone for patients undergoing laparoscopic cholecystectomy. Kathmandu Univ Med J 2008;6(23):31928. https://doi: 10.3126/kumj. v6i3.1706.

20. Yu WY, Li QJ, Wui CX, Gong JP. The Prophylaxis and Treatment with Ondansetron for Postoperative Nausea and Vomiting. Surg Curr Res 2015; 5:224. https://doi:10.4172/21611076.1000224
21. Jin Z, Gan TJ, Bergese SD. Prevention and Treatment of Postoperative Nausea and Vomiting (PONV): A Review of Current Recommendations and Emerging Therapies. Ther Clin Risk Manag. 2020 31; 16:1305-1317. https://doi 10.2147/TCRM.S256234.

22. Elvir-Lazo OL, White PF, Yumul $\mathrm{R}$ and Cruz Eng $\mathrm{H}$. Management strategies for the treatment and prevention of postoperative/postdischarge nausea and vomiting: an updated review F1000Research 2020; 9:983. https://doi.org/10. 12688/f1000research.21832.1

23. Ahsan K, Abbas N, Naqvi SM, Murtaza G, Tariq S. Comparison of efficacy of ondansetron and dexamethasone combination and ondansetron alone in preventing postoperative nausea and vomiting after laparoscopic cholecystectomy. J Pak Med Assoc. 2014 Mar 1;64(3):242-6.

24. Maqbool MS, Alam M, Draz MU, Shahid A, Ashfaq S. Anaesthesia Concern in High-Risk Cases Under-Going Ambulatory Laparoscopic Cholecystectomy. J Bahria Uni Med Dental Coll. 2021; 11(4):179-183. https://doi.org /10.51985/JBUMDC2021045

25. Si XY, Wu LP, Li XD, Li B, Zhou YM. Dexamethasone combined with other antiemetics for prophylaxis after laparoscopic cholecystectomy. Asian J Surg. 2015;38(1):217. https://doi: 10.1016/j.asjsur.2014.04.005. 